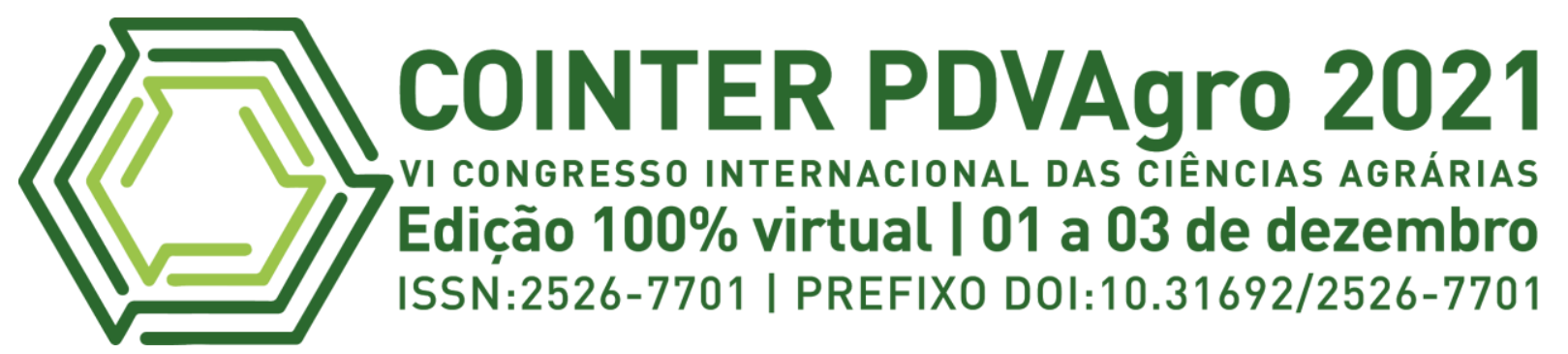

\title{
ANÁLISE DE USO E COBERTURA DO SOLO ASSOCIADA A FOCOS DE CALOR NO MUNICÍPIO DE BANNACH - PA
}

\section{ANÁLISIS DE USO Y COBERTURA DE SUELOS ASOCIADOS A SALIDAS DE CALOR EN EL MUNICIPIO DE BANNACH - PA}

\section{ANALYSIS OF USE AND SOIL COVERAGE ASSOCIATED WITH HEAT OUTPUTS IN THE MUNICIPALITY OF BANNACH - PA}

\author{
Apresentação: Comunicação Oral \\ Gabriel Garreto dos Santos ${ }^{1}$; João Paulo Ferreira Neris²; Jameles Silva de Sousa ${ }^{3}$ Valéria Sousa da Silva ${ }^{4}$; Tatiana \\ Pará Monteiro de Freitas 5
}

DOI: https://doi.org/10.31692/2526-7701.VICOINTERPDVAgro.0033

\section{RESUMO}

O presente estudo objetivou analisar os dados de focos de queimadas e uso e cobertura do solo entre os anos de 2000 a 2019 no município de Bannach-PA. Os dados provenientes dos focos de queimadas foram obtidos no formato vetorial na extensão shapefile (SHP) a partir dos satélites: AQUA, ATSR, METOP, MSG, NOAA, NPP, TRMM, TERRA, GOES do sensor MODIS por permitir analisar as informações sobre o fenômeno e suas tendências temporais. Os dados de uso e cobertura do solo foram obtidos por meio de imagens de satélites fornecidos pelo programa Mapbiomas. Em relação aos focos de queimadas para os anos estudados, observou-se que, em quase toda a extensão do município foi recoberta pelos focos de queimadas, com maior disposição nos anos de $2005 \mathrm{com}$ 30,08\%, $2010 \mathrm{com}$ $25,55 \%$ e $2015 \mathrm{com} 22,85 \%$. As menores taxas de ocorrência ocorreram no ano inicial e final da série com 3,29\% e 18,23\% para 2000 e 2019 respectivamente. A partir das imagens de satélites e dos dados estatísticos para cada classe de uso e cobertura do solo do município de Bannach, coletados através do Mapbiomas verificou-se, uma maior expansão para a classe de agropecuária de 46,64\% e redução de $56,20 \%$ para a classe de floresta. Inferindo que o desmatamento na região está associado aos processos produtivos do município. Por isso, é necessário que sejam adotados modelos de produção mais sustentáveis com impactos ambientais reduzidos na região, que alie produção e conservação do meio ambiente. Os SAF é uma excelente opção em decorrência desses sistemas substituírem o desmatamento e as queimadas por práticas de manejo mais sustentáveis como a recomposição da paisagem florística e recuperação de solos degradados e ainda nesse processo, sendo possível alcançar uma maior produção e diversificação de produtos agrícolas. Por fim, aliada a essas premissas o uso de geotecnologias em especial do SIG, mostrou-se como uma ferramenta bastante promissora e de fundamental importância

\footnotetext{
${ }^{1}$ Agronomia, Instituto Federal do Pará - IFPA, gabryelgarreto@gmail.com

2 Agronomia, Instituto Federal do Pará - IFPA, paulonerisfer1@ gmail.com

3 Agronomia, Instituto Federal do Pará - IFPA, jhamelles8296@gmail.com.br

${ }^{4}$ Medicina Veterinária, Universidade Federal do Pará - UFPA, valeria.silva@ castanhal.ufpa.br

${ }^{5}$ Mestre em Desenvolvimento Sustentavél e Gestão Rural, Instituto Federal do Pará - IFPA, tatiana.para@ifpa.edu.br
} 


\title{
ANÁLISE DE USO E COBERTURA DO SOLO ASSOCIADA A FOCOS DE CALOR NO MUNICÍPIO DE BANNACH - PA
}

no alcance de resultados de dados espacializados, pois essas informações são necessárias para o delineamento de políticas públicas e para tomada de decisão para a prevenção, monitoramento e ao combate das queimadas, e acompanhamento das transformações locais da paisagem e das modificações ambientais em municípios amazônicos.

Palavras-Chave: Desmatamento, Amazônia, Sustentabilidade, Metodologia de Kernel.

\section{RESUMEN}

Este estudio tuvo como objetivo analizar datos sobre focos de incendios y uso y cobertura del suelo entre los años 2000 a 2019 en el municipio de Bannach-PA. Los datos de los focos de incendios se obtuvieron en formato vectorial en extensión shapefile (SHP) de los satélites: AQUA, ATSR, METOP, MSG, NOAA, NPP, TRMM, TERRA, GOES del sensor MODIS porque permite analizar la información sobre el fenómeno y sus tendencias temporales. Los datos de uso y cobertura del suelo se obtuvieron a través de imágenes de satélite proporcionadas por el programa Mapbiomas. En cuanto a los focos de incendios para los años estudiados, se observó que, en casi toda la extensión del municipio, estuvo cubierto por focos de incendios, con mayor disposición en los años de 2005 con 30,08\%, 2010 con 25,55\% y 2015 con $22,85 \%$. \%. Las tasas de ocurrencia más bajas ocurrieron en el año inicial y final de la serie con $3.29 \%$ y $18.23 \%$ para 2000 y 2019, respectivamente. A partir de imágenes satelitales y datos estadísticos para cada clase de uso del suelo y cobertura del suelo en el municipio de Bannach, recolectados a través de Mapbiomas, se verificó una mayor expansión para la clase agrícola del 46,64\% y una reducción del $56,20 \%$ para la clase forestal. . Inferir que la deforestación en la región está asociada a los procesos productivos del municipio. Por tanto, es necesario adoptar modelos de producción más sostenibles con impactos ambientales reducidos en la región, que combinen producción y conservación del medio ambiente. El SAF es una excelente opción ya que estos sistemas reemplazan la deforestación y los incendios con prácticas de manejo más sustentables como la restauración del paisaje florístico y la recuperación de suelos degradados, e incluso en este proceso, es posible lograr una mayor producción y diversificación de productos agrícolas. . Finalmente, aliado a estas premisas, el uso de geotecnologías, especialmente SIG, resultó ser una herramienta muy prometedora y de fundamental importancia para lograr resultados de datos espacializados, ya que esta información es necesaria para el diseño de políticas públicas y para la toma de decisiones para la prevención, monitoreo y combate de incendios y monitoreo de las transformaciones locales en el paisaje y cambios ambientales en los municipios amazónicos.

Palabras Clave: Deforestación, Amazonia, Sostenibilidad, Metodología Kernel.

\begin{abstract}
This study aimed to analyze data on fire outbreaks and land use and cover between the years 2000 to 2019 in the municipality of Bannach-PA. The data from the fire outbreaks were obtained in vector format in shapefile extension (SHP) from the satellites: AQUA, ATSR, METOP, MSG, NOAA, NPP, TRMM, TERRA, GOES from the MODIS sensor because it allows analyzing the information about the phenomenon and its temporal trends. Land use and land cover data were obtained through satellite images provided by the Mapbiomas program. Regarding the fire outbreaks for the years studied, it was observed that, in almost the entire extension of the municipality, it was covered by fire outbreaks, with greater disposition in the years of 2005 with $30.08 \%, 2010$ with $25.55 \%$ and 2015 with $22.85 \%$. The lowest occurrence rates occurred in the initial and final year of the series with $3.29 \%$ and $18.23 \%$ for 2000 and 2019, respectively. From satellite images and statistical data for each class of land use and land cover in the municipality of Bannach, collected through Mapbiomas, it was verified a greater expansion for the agricultural class of $46.64 \%$ and a reduction of 56, 20\% for the forest class. Inferring that deforestation in the region is associated with the municipality's production processes. Therefore, it is necessary to adopt more sustainable production models with reduced environmental impacts in the region, which combine production and conservation of the environment. The SAF is an excellent option as these systems replace deforestation and fires with more sustainable management practices such as the restoration of the floristic landscape and recovery of degraded soils, and even in this process, it is possible to achieve greater production and diversification of agricultural products. Finally, allied to these
\end{abstract}


premises, the use of geotechnologies, especially GIS, proved to be a very promising tool and of fundamental importance in achieving spatialized data results, as this information is necessary for the design of public policies and for taking decision-making for the prevention, monitoring and combating of fires, and monitoring of local transformations in the landscape and environmental changes in Amazonian municipalities.

Keywords: Deforestation, Amazon, Sustainability, Kernel Methodology.

\section{INTRODUÇÃO}

O uso irracional do fogo como forma disseminadora e prospecção de áreas desflorestadas para o manejo da terra, tem-se mostrado muito presente nos dias atuais na região amazônica por ser considerada de baixo custo e de aspecto cultural na agricultura. Assim, é comum em período de estiagem, quando a umidade do solo é baixa e a temperatura do ar é alta, observar tal prática sendo executada. Nesse tocante, segundo Sales et al., (2019) as queimadas na Amazônia estão fortemente associadas às práticas culturais exercidas por pequenos e grandes produtores rurais em atividades econômicas, como a agricultura e pecuária.

Não obstante, o agravamento dos índices de queimadas colaboram para o surgimento e aumento de doenças respiratórias, além de contribuir na emissão dos gases do efeito estufa, colocando o nosso planeta em alerta, tanto no aumento da temperatura quanto nas mudanças climáticas. Para Bastos et al., (2006) o número de incêndios no contexto amazônico reflete um cenário preocupante que ocasiona impactos socioeconômicos e ambientais, como a degradação da biodiversidade e da paisagem, juntamente com efeitos negativos na saúde humana e na economia de populações rurais que dependem das florestas para a obtenção de produtos extrativistas que são destinados para a comercialização e sustento dessas famílias.

Para Thomaz et al., (2014) uma área classificada como foco de calor são aquelas, às quais se encontra em grau de temperatura elevada a mais de $47{ }^{\circ} \mathrm{C}$ e sendo esse fenômeno detectados quase sempre através de satélites orbitais, constituindo parte importante do sistema de monitoramento de incêndios florestais.

As ocorrências de queimadas no Brasil sempre vêm permutadas com o avanço das fronteiras agrícolas, e a cada ano tem gerado debates, entre o governo brasileiro e nações globais que viam este país como grande propulsor da sustentabilidade no meio onde o homem vive, planta e colhe. Grandes comunidades de discussão climática fazendo ressalvas que possam buscar alternativas de se plantar, colher e produzir de forma consciente e transparente, ou seja, de forma mais sustentável sem agredir os lençóis freáticos, bioma ou flora brasileira.

$\mathrm{Na}$ Amazônia, com a expansão das fronteiras agrícolas, assim como a modernização da agricultura e da pecuária, estão entre os fatores que mais contribuem para a descaracterização 


\section{ANÁLISE DE USO E COBERTURA DO SOLO ASSOCIADA A FOCOS DE CALOR NO MUNICÍPIO DE BANNACH - PA}

da vegetação original, impactando também a biodiversidade, os solos e as águas (Lorena, 2003).

Nesse cenário, o manejo e conservação do solo no município de Bannach-PA está atrelado a fatores de avanço da atividade agropecuária, que por sua vez contribuem para o empobrecimento de micro e macro nutrientes dos solos amazônicos. No Estado do Pará, a ocupação e o uso do solo estão inteiramente ligados também à expansão dos focos de calor (FERNANDES, 2019).

Diante da temática o presente trabalho objetivou analisar a espaço-temporalidade dos dados cartográficos de focos de calor entre os anos de 2000, 2005, 2010, 2015 e 2019 e de uso e cobertura do solo do município de Bannach, utilizando produtos do sensoriamento remoto e técnicas de geoprocessamento.

\section{FUNDAMENTAÇÃO TEÓRICA}

Partimos então do pressuposto de Ramos (2011), assumindo que o registro de um índice alto de queimadas em dadas regiões pertencentes aos territórios amazônicos possui associação direta com os desmatamentos, que têm ocorrido em suma nas mesmas áreas, estando relacionados com os modos e formas de uso e ocupação da terra. Assim, os maiores registros do desmatamentos e de queimadas na Amazônia, têm sua origem de atividades antrópicas, cedendo espaço para a imersão do gado e da lavoura da soja em larga escala, em espaços que um dia foram ocupadas por vegetação primária (RAVEIRO, 2009).

Nesse contexto, o desenvolvimento dos territórios amazônicos sempre esteve alinhado com a prática de atear fogo sob a vegetação e para atingir objetivos específicos tanto nas atividades de agricultura como no processo de derruba e queima para a inserção de novas roças como também na pecuária para o manejo e rebrota das pastagens e operações agrícolas (VAN DER WERF et al., 2010).

Segundo Schroeder et al., (2009), o fogo na Amazônia é dividido em quatro categorias que são: fogo de desmatamento, fogo de manutenção, fogo acidental e o fogo natural, onde somente o fogo natural não está relacionado diretamente com a ação humana. Entretanto, relacionado com as mudanças de clima, em anos de seca severa o perigo de queima natural em regiões florestais e não florestais, têm grande probabilidade de se expandir notavelmente (VASCONCELOS et al., 2015).

Contudo, incêndios florestais na Amazônia dificilmente acontecem de maneira natural elas precisam de um agente de ignição antrópica, ou em outras palavras que alguém coloque fogo sob a vegetação (BERENGUER et al., 2019). Nesse contexto, o bioma Amazônia tem sofrido um grande agravo desde o ano de 2019, com relação a áreas queimadas, a floresta tem 
queimado de forma mais acelerada onde fenômenos de origem climática não justifica esse crescimento crítico e destruidor (IPAM, 2019). O que nos leva a deduzir que a origem desses incêndios, nos municípios amazônicos nos últimos anos assim, como na cidade de Bannach são propositais e notavelmente com a participação humana nesse processo, em que o fogo é usualmente empregado com uma finalidade específica, seja ela agrícola ou pecuarista.

Agrega-se ainda sobre essa discussão Filho et al., (2014) desponta como principal vetor do desmatamento na região amazônica a criação de animais como a do gado por exemplo, onde não existe ainda um controle específico. Pelo contrário, tem na verdade um aumento do consumo de carne bovina pelo ser humano, tanto em nível nacional quanto em escala global, aliado aos grandes empreendimentos de infraestrutura e as mudanças climáticas, oferecem um cenário preocupante de aumento da pressão sobre as florestas.

Corroborando com o raciocínio Arraes et al., (2010), também menciona que um dos principais agentes causadores do desmatamento é a pecuária, visto que é uma atividade na qual proporciona um retorno econômico em um curto período. Isto pode ser observado com o que ocorre no município de Bannach, tendo como principal uso da terra a pecuária de corte, seguido pelo extrativismo.

Nesse sentido, até que medidas de proteção sejam tomadas contra os desmatamentos e as queimadas pelas instâncias responsáveis como forma de frear esse cenário nefasto de destruição dos recursos naturais. Torna-se de extrema importância a inserção de tecnologias digitais para mitigar tais fenômenos e que sejam favoráveis a fiscalização dessas mudanças ocorridas no território e sobre a sua paisagem. Nesse processo o uso de geotecnologias já se despontam como ferramenta basilar para esse processo de monitoramento das mudanças ambientais ocorridas ao longo dos anos, principalmente se tratando do geoprocessamento, sensoriamento remoto e dos sistemas de informações geográficas.

Conforme Zaidan, (2017), o geoprocessamento é conjunto de técnicas e métodos teóricos e computacionais relacionados com a coleta, entrada, armazenamento, tratamento e processamento de dados, a fim de gerar novos dados ou informações espaciais ou georreferenciadas. Tratando-se do Sensoriamento Remoto (SR) por sua vez, pode ser definido como a técnica de adquirir de imagens de alta precisão e resolução dos objetos da superfície presentes na superfície da terra, sem que haja nenhum contato físico de qualquer espécie entre o sensor e o objeto de análise (MENESES e ALMEIDA, 2012). Já os Sistemas de Informações Geográficas (SIGs), podem ser considerados uma das geotecnologias que se encontram dentro do escopo de tarefas do geoprocessamento. Um SIG é um sistema constituído e operacional. Uma definição clássica de SIG seria a de um sistema automatizado de coleta, armazenamento, 


\section{ANÁLISE DE USO E COBERTURA DO SOLO ASSOCIADA A FOCOS DE CALOR NO MUNICÍPIO DE BANNACH - PA}

manipulação e saída de dados cartográficos (BURROUGH e MCDONNELL, 1998).

Baseado no uso dessas tecnologias supracitadas diferentes autores têm estudado o comportamento de focos de queimadas e dos desmatamentos em municípios amazônicos. Souza et al., (2021) estudando a dinâmica de uso e cobertura da terra associados a focos de calor no município de Poconé/MT, concluíram que boa parte das queimadas analisadas no município em questão estavam concentradas em áreas de preservação, ocasionando impactos ambientais que afetam tanto a população da região quanto a biodiversidade local e que a expansão do desmatamento e do elevado índice de focos de queimadas na região, pertencente ao município estão associados com fatores produtivos especialmente da pecuária extensiva.

Nessa perspectiva, estudos acerca da dinâmica dos focos de incêndio são elementos primordiais para melhor entender quais as causas do fogo, bem como também para afirmar o avanço na fiscalização, monitoramento, controle e combate ao fogo, conforme mencionado no estudo de Santos et al., (2020). Por esse motivo, a análise de séries temporais com dados de desmatamento e de focos de queimadas por meio de a suposição com dados de geoprocessamento auxiliarão para um maior entendimento do processo de risco de incêndio e a evolução de procedimentos eficientes de alertas prévio (HUESCA et al., 2014).

\section{METODOLOGIA}

\section{Área de estudo}

O estudo foi realizado no município de Bannach, estado do Pará, localizado na região Norte do Brasil (Figura 01), situado a $870 \mathrm{~km}^{2}$ aproximadamente da capital Belém, insere-se totalmente no bioma Amazônia. De acordo com o IBGE (2020), o município possui uma população estimada em 3.431 habitantes na localidade. E apresentando uma extensão de 2.956,649 $\mathrm{km}^{2}$ da área territorial considerado um dos menores municípios paraenses (IBGE, 2020).

Bannach é confrontante com as cidades de Ourilândia do Norte e Água Azul do Norte ao Norte, ao sul com os municípios de Cumaru do Norte e Redenção, ao leste com Xinguara, Rio Maria e Pau D' Arco e a oeste também com a cidade de Cumaru do Norte. Está situada entre os seguintes pares de coordenadas geográficas $7^{\circ} 20^{\prime} 52^{\prime \prime} \mathrm{S}$ de latitude e $50^{\circ} 23^{\prime} 45^{\prime \prime} \mathrm{O}$ de longitude. 
Figura 01: Mapa de localização do município de Bannach, Pará.

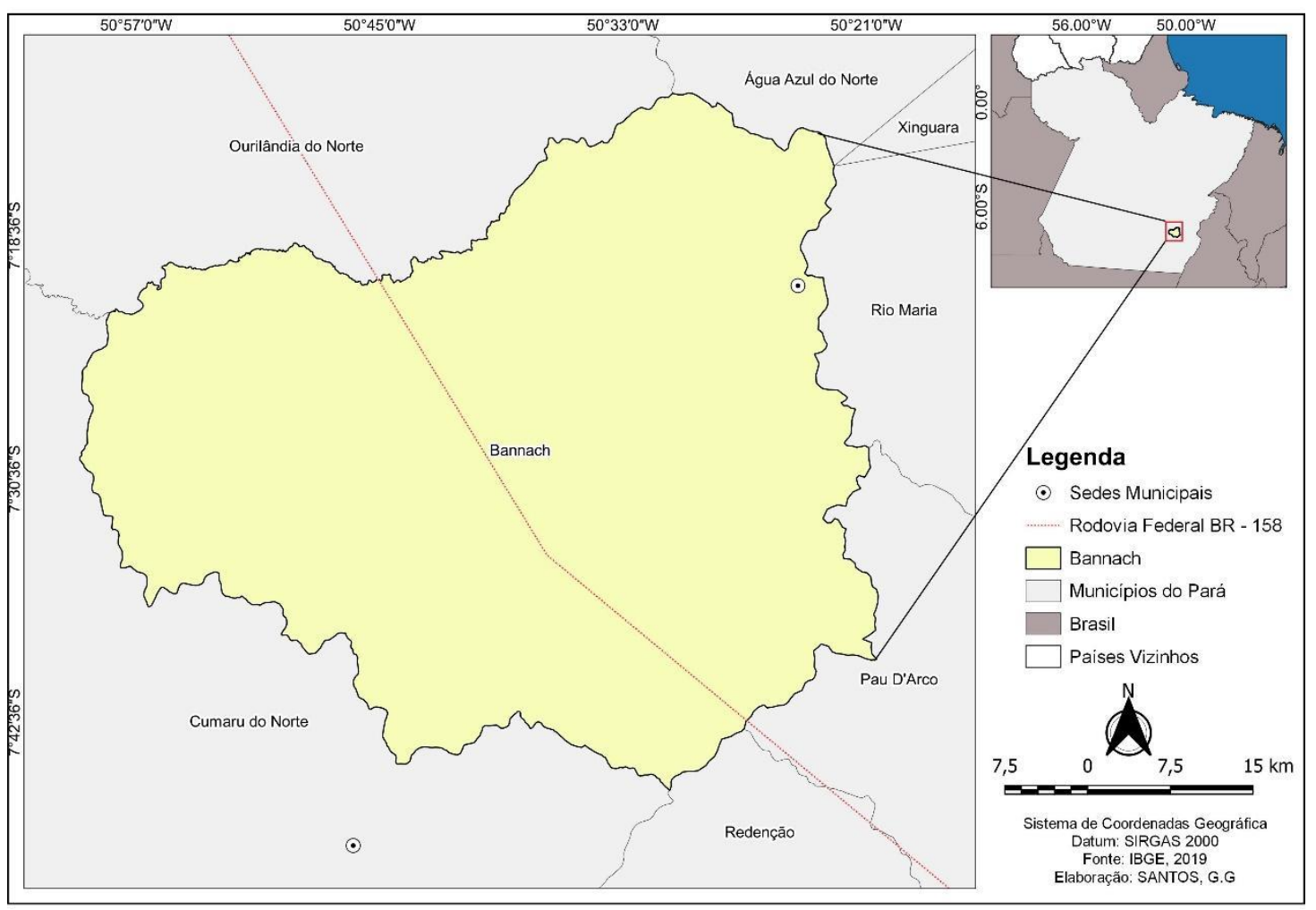

Fonte: Dos Santos, 2021

O município de Bannach foi criado no ano de 1997, integrando parte da bacia amazônica e apresenta em seu território vegetação típica da Floresta Amazônica. Segundo Köppen, o clima da região é caracterizado como AW em que está condicionado a valores de precipitação pluviométrica média anual, que variam entre 2000 a $2500 \mathrm{~mm}$.

Os solos da área de estudo são predominantemente compostos por Argissolos Vermelho Amarelo, estando estes inseridos nas áreas com declividade plana. Na classe de declive suave ondulado encontram-se os Latossolos Vermelhos Amarelos e os Nitossolos Vermelhos. Já na classe de declive fortemente ondulado encontram-se os Neossolos Litólicos (ARRAES et al., 2010).

\section{Base Cartográfica}

O presente trabalho utilizou-se de diferentes bases de dados incluindo eles a base cartográfica do Instituto Brasileiro de Geografia e Estatística (IBGE), Instituto Nacional de Pesquisas Espaciais (INPE), Departamento Nacional de Infraestrutura de Transportes (DENIT) e do Projeto MapBiomas. 


\section{ANÁLISE DE USO E COBERTURA DO SOLO ASSOCIADA A FOCOS DE CALOR NO MUNICÍPIO DE BANNACH - PA}

\section{Processamento dos dados Espaciais}

\section{Mapas de focos de calor}

O processamento foi realizado através de informações espaciais (focos de calor -cujo os dados foram obtidos a partir do banco de queimadas o Bdqueimadas disponível pelo INPE). Os dados são referentes ao sensor MODIS, presente nos respectivos satélites: AQUA, ATSR, METOP, MSG, NOAA, NPP, TRMM, TERRA, GOES. Foram disponíveis em planilha eletrônica dados diários sobre a quantidade de focos de calor nos meses estudados e assim foram realizados gráficos comparativos de taxas de focos de queimadas por ano (SOUZA et al., 2021).

A identificação das zonas de queimadas foram definidas em ambiente SIG, onde foi modelado o padrão de distribuição do conjunto de pontos, utilizando-se o estimador de densidade Kernel, obtendo como produtos finais, dados matriciais de densidade dos focos de calor entre os anos de 2000, 2005, 2010, 2015 e 2019.

Este interpolador é bastante utilizado para geração de uma superfície contínua por meio de dados amostrais, geralmente dados esses do tipo pontos. Este tipo de operação é realizado a partir pelo de uma função bidimensional aos eventos considerados, onde, esta função realiza uma contagem de todos os pontos dentro de uma dada área de influência. No qual, esses pontos são ponderados pela distância de cada um até o ponto que está sendo estimado (DRUCK et al., 2004). Este processo possibilita um produto final com uma visão qualitativa dos focos de calor na região de interesse.

Para representação cartográfica das informações, e a fim de melhor representação e análise dos resultados da interpolação, foram definidas 5 classes de densidade: 1) muito baixa, 2) baixa, 3) média, 4) alta e 5) muito alta. O software utilizado neste processamento foi o QGIS 3.16 e a sua extensão interpolar usando o complemento mapa de calor.

\section{Mapeamento de uso e cobertura do solo}

O processamento de dados de Uso e Cobertura do solo foram derivados da coleção de imagens adquiridas do Projeto MapBiomas, em que a partir do arquivo vetorial em extensão shapefile do município em estudo, foi recortada as imagens do MapBiomas e para cada imagem foi processado de maneira a extrair, com o uso do SIG, a área de cada tipo de uso da terra para os anos de 2000, 2005, 2010, 2015 e 2019. No qual, essas imagens já são previamente processadas pelo MapBiomas. Utilizou-se apenas o Software QGIS 3.16, para extrair as classes de cobertura do solo e de maneira a identificá-las, cartograficamente na legenda dos mapas. 
As seguintes classes foram referentes à própria biografia do MapBiomas adaptada para o mapeamento de uso e cobertura do solo para o município de Bannach, utilizando as classes Floresta e Agropecuária para os mapeamentos. E para elaboração da tabela no Excel com os valores em hectares e em percentuais adquiridos no MapBiomas, foram utilizados as classes Floresta, Agropecuária, Formação Natural não Florestal, Área não vegetada, Corpo D’Água. A justificativa de não utilizar todas as cinco classes para o mapeamento firmou-se pelo tamanho reduzido dessas classes e pela difícil visualização das mesmas nos mapas temáticos de uso e cobertura do solo no município em estudo.

Nesse sentido, o projeto Mapbiomas é uma iniciativa que envolve uma rede colaborativa com diferentes especialistas nos biomas, usos da terra, sensoriamento remoto, SIG (Sistema de Informação Geográfica) e ciência da computação. Estes, utilizam processamento em nuvem e classificadores automatizados desenvolvidos e operados a partir da plataforma Google Earth Engine para gerar uma série histórica de mapas anuais de cobertura e uso da terra do Brasil. No qual, esses mapas possuem melhor aplicação em escalas até 1:100.000 e são gerados a partir de imagens do satélite LANDSAT 8, com resolução espacial de alcance de 30 metros. Dessa maneira, cada pixel das imagens é classificado, entre 27 classes de uso da terra (MAPBIOMAS, 2021).

\section{RESULTADOS E DISCUSSÃO}

Por meio das informações, obtidas através de dados dos satélites do INPE, utilizados na série, verificou-se que, entre os anos estudados no município de Bannach-PA, registrou um número de 8.934 focos de calor no período intercalado de 5 anos entre os anos de 2000, 2005, 2010, 2015 e 2019.

A Tabela 01, demonstra dados de focos de calor do ano de 2000 a 2019, a partir desta, infere-se que aproximadamente $88,19 \%$ dos focos de calor estão presentes nos meses de agosto a setembro. Para Rodrigues et al., (2020), esses focos e ao mesmo tempo os números que crescem demasiadamente estão associados com a falta de chuvas nessa época do ano sobre os biomas brasileiros.

Nos últimos anos o elemento fogo é provocado sobretudo pela execução de práticas de manejo inadequado da terra que acabam afetando diretamente o meio ambiente colocando em risco os diferentes ecossistemas do mundo em escalas globais (Ramos et al., 2018). 


\section{ANÁLISE DE USO E COBERTURA DO SOLO ASSOCIADA A FOCOS DE CALOR NO MUNICÍPIO DE BANNACH - PA}

Tabela 01: Dados mensais dos focos de calor no município de Bannach-PA

\begin{tabular}{lccccc}
\hline Mês/Ano & $\mathbf{2 0 0 0}$ & $\mathbf{2 0 0 5}$ & $\mathbf{2 0 1 0}$ & $\mathbf{2 0 1 5}$ & $\mathbf{2 0 1 9}$ \\
\hline Janeiro & 0 & 0 & 0 & 4 & 0 \\
Fevereiro & 0 & 0 & 8 & 0 & 1 \\
Março & 0 & 0 & 0 & 0 & 1 \\
Abril & 0 & 0 & 0 & 0 & 1 \\
Maio & 0 & 0 & 0 & 0 & 13 \\
Junho & 0 & 0 & 6 & 1 & 0 \\
Julho & 1 & 264 & 14 & 13 & 7 \\
Agosto & 273 & 2052 & 1317 & 157 & 793 \\
Setembro & 20 & 352 & 761 & 1388 & 766 \\
Outubro & 0 & 18 & 174 & 457 & 34 \\
Novembro & 0 & 1 & 1 & 19 & 13 \\
Dezembro & 0 & 0 & 1 & 3 & 1 \\
\hline Total & 294 & 2687 & 2282 & 2042 & 1629 \\
\hline
\end{tabular}

Fonte: INPE, (2021).

Dessa forma, Soriano et al., (2020) corrobora que o fogo controlado depende das condições meteorológicas do período mensal e da vegetação sobre o bioma e as cidades que a compõem. O gráfico 01, apresenta dados dos focos de calor dos anos de 2000 a 2019, nesse período identifica-se um crescente aumento dos focos de calor de 813,19\% do ano de 2000 para 2005.

De 2005 para 2010 houve uma redução de 15,07\%. Enquanto de 2010 para 2015 e de 2015 até 2019 ocorreu novas reduções quando comparadas aos anos anteriores, essas reduções foram de 10,51, 20,22\% respectivamente. algo que certamente é bom para o meio ambiente e para a população local deste município. Em decorrência do fogo trazer sérios problemas ambientais como destruição em massa da biodiversidade de fauna e flora e também por promover problemas relacionados à saúde pública com emissões de gases poluentes.

Gráfico 01: Total anual de focos de calor no município de Bannach-PA

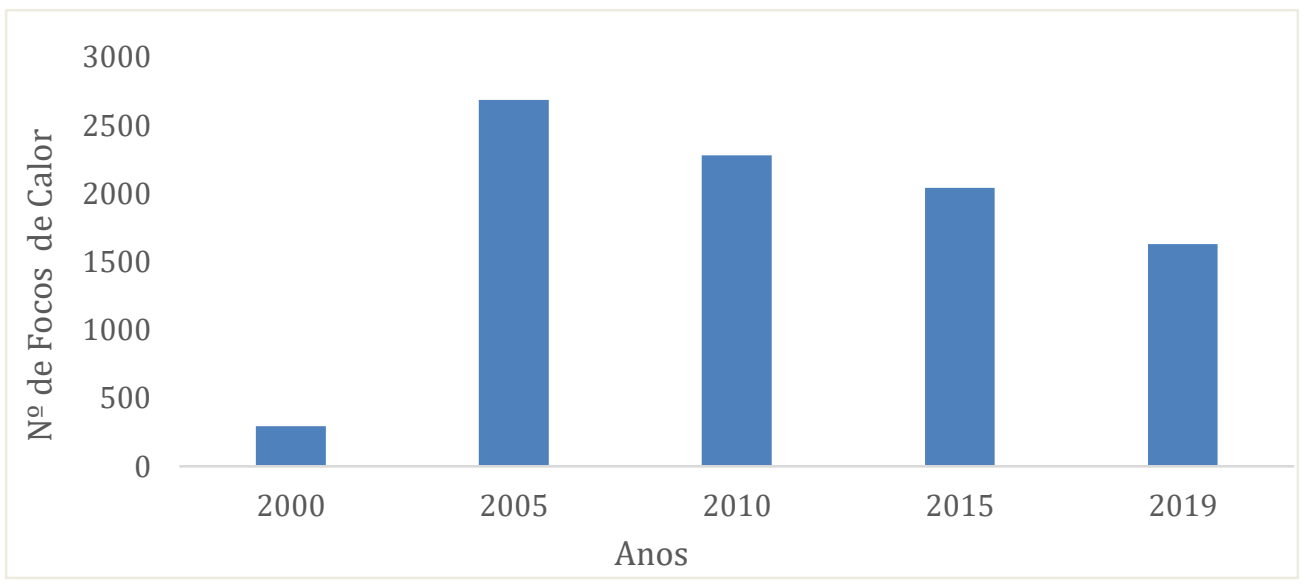

Fonte: Autores, 2021 
A Figura 02, expõe a espacialização dos focos de calor dos anos 2000, 2005, 2010, 2015 e 2019, a partir das imagens verifica-se que apesar do ano de 2000 haver um índice menor de focos de calor com cerca de 3,29\% dos focos na série estudada, eles estão muito mais espalhados pelos territórios do município, predominando a classe alta e muita alta desses focos na região central se estendendo no sentido norte e leste. $\mathrm{O}$ ano seguinte, em 2005, alcançou a maior concentração de focos durante todos os intervalos em análise com 30,07\% do total. No qual, podemos observar um padrão similar do comportamento desses focos sob o território igual ao ano de 2000. No entanto, existe um maior deslocamento das classes alta e muito alta que estão mais situadas na região central do município, deslocando-se no sentido oeste e leste de Bannach.

Em 2010 os focos de calor encontraram uma taxa de $25,54 \%$ do total dos focos observados. Nesse mesmo período o fenômeno assume uma tendência mais centralizada com expansão desses focos para a região oeste do município, principalmente com relação às classes alta e muito alta. Diferente dos outros anos (2015 e 2019) com 22,85\% e 18,23\% respectivamente do total dos focos estudados, no qual, passaram a ter deslocamentos desses focos de forma mais adensadas e concentrados em um único local com maiores concentrações principalmente com relação às classes alta e muito alta das queimadas na região.

No ano de 2015 os focos estão mais posicionados na região norte do município e em 2019 alcançou um maior número de focos com a representação de classes de densidades alta e muito alta na porção oeste do município em proximidades com a Terra índigena Kayapó que possuem, mesmo com as pressões sofridas nas terras os maiores contrastes de vegetação natural de Bannach. Esses fatos supracitados ocorrem na região em decorrência do desmatamento e da queima de áreas para implantação de outros usos e coberturas do solo como de agricultura e pecuária principalmente que são as principais atividades socioeconômicas do Sul e Sudeste do Pará.

Martinez et al., (2007) em Terra do Meio, municípios de Altamira e São Félix do Xingu, Estado do Pará, estudaram a relação entre o desflorestamento e os focos de calor entre 1998 a 2002, verificaram que a área total desflorestada aumentou mais de quatro vezes, fato impulsionado principalmente pela conversão de grandes áreas de florestas em pastagens, concomitante ao avanço e consolidação da fronteira agrícola com a pecuária. Ou seja, a pecuária é considerada um dos principais vetores de desmatamento e queimadas em municípios paraenses, e essa realidade não é distinta do município de Bannach que possui como principal atividade econômica a pecuária extensiva.

Corroborando com essas afirmativas Arraes et al., (2010) estudando a taxa de 


\section{ANÁLISE DE USO E COBERTURA DO SOLO ASSOCIADA A FOCOS DE CALOR NO MUNICÍPIO DE BANNACH - PA}

desmatamento no município de Bannach com imagens de satélites, chegaram em suas conclusões que o desflorestamento está rotineiramente associado e estabelecido no processo produtivo da Amazônia, constituindo um dos elementos centrais que impulsiona a expansão agrícola na região e, é responsável pela substituição de áreas de vegetação nativa por extensas áreas de pastagens neste município.

Nesse raciocínio, segundo Ramos (2011) pesquisadores do INPE assume que 99\% das queimadas são provocadas pelo homem e que as condições atmosféricas favorecem os incêndios, contudo as principais causas mediadoras desse processo são institucionalizadas pelas atividades econômicas e culturais de seus territórios.

Figura 02: Mapas de Focos de calor de 2000, 2005, 2010, 2015, 2019.

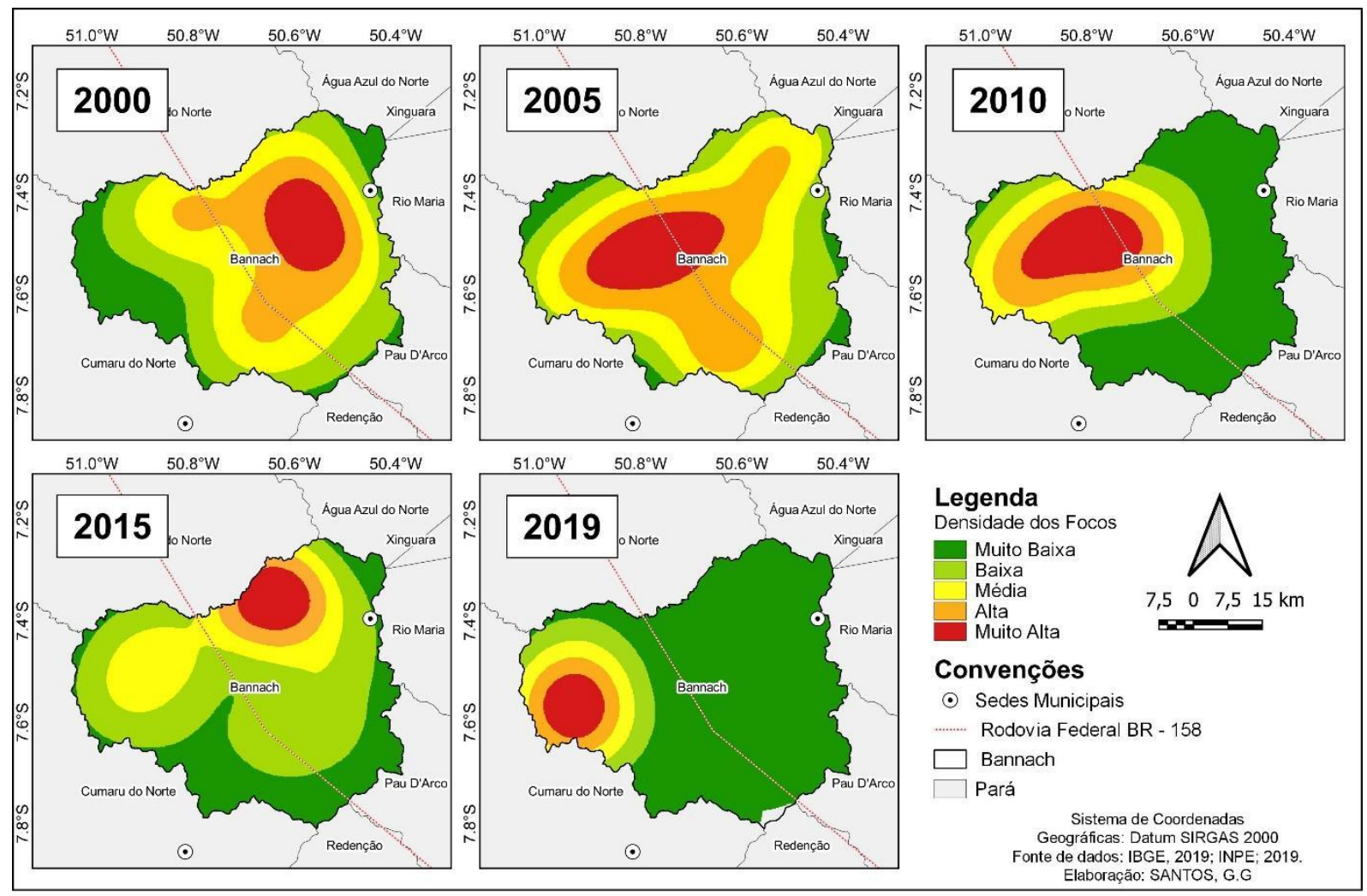

Fonte: Autores, 2021

Como resultado da análise das imagens de satélites adquiridas pelo Mapbiomas, do uso e cobertura do solo, processadas de maneira a extrair, com o uso do SIG, a área de cada tipo de uso da terra para os anos estudados, evidenciou-se cinco classes, as quais são: Floresta, formação natural não florestal, agropecuária, área não vegetada e corpo d'água. No entanto, só é possível analisar as distintas classes de uso e cobertura do solo no município em escala 
ampliada no SIG. Em decorrência disso, optamos em expressar nos mapas temáticos apenas as classes aparentes, visualmente que são Floresta e Agropecuária (Figura 03).

Figura 03: Mapas de Uso e Cobertura do Solo no município de Bannach-PA.

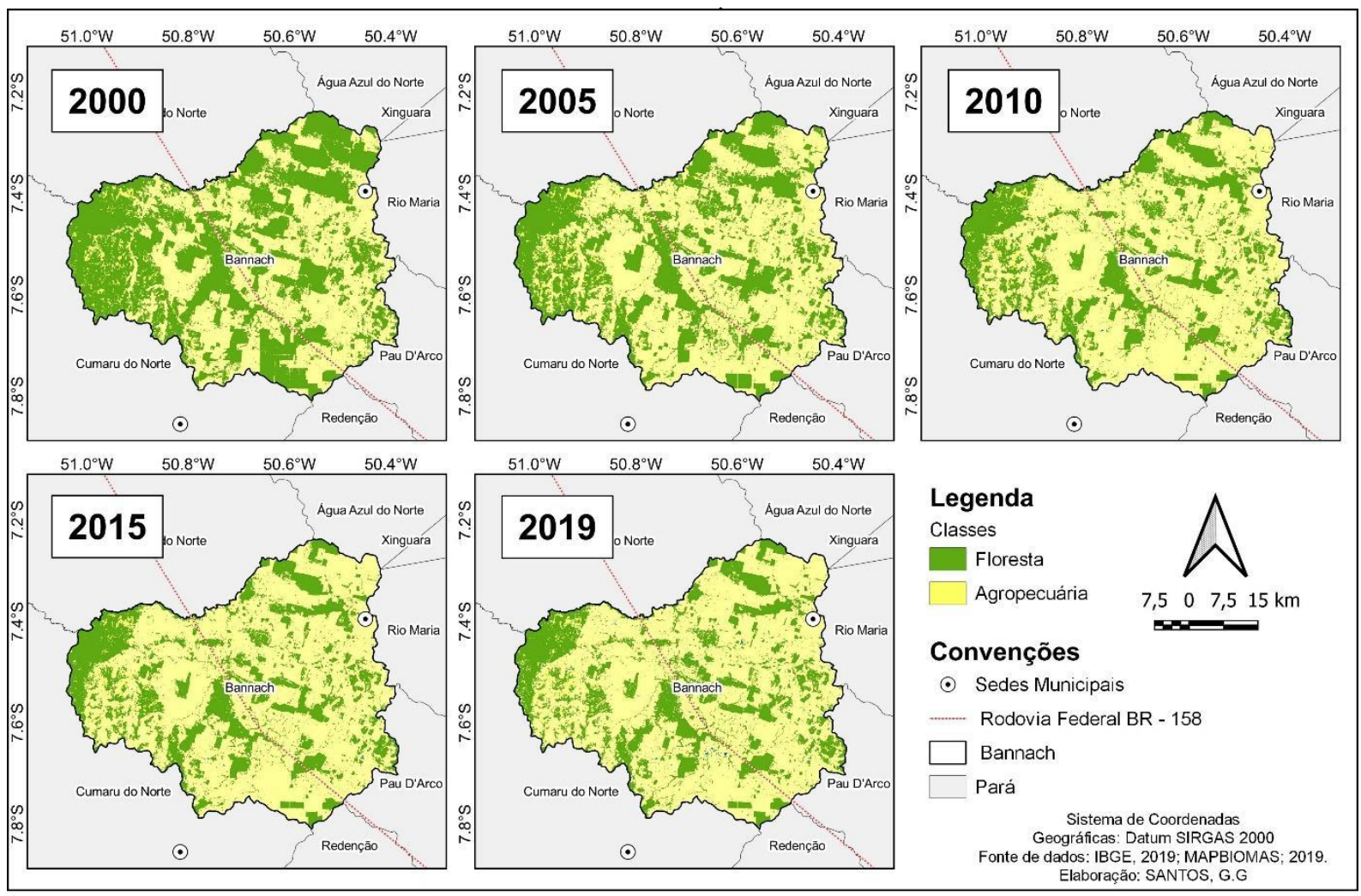

Elaborado com base nos dados do MapBiomas. Fonte: Autores (2021)

Enquanto que na tabela 02, podemos observar todos os valores percentuais e também em hectares, para as cinco classes: Floresta, formação natural não florestal, agropecuária, área não vegetada e corpo d'água. Conforme é encontrado na plataforma Mapbiomas para a cidade de Bannach. Para a análise da tabela supracitada, não houve necessidade de fazer mudanças na representatividade das classes como nos mapas em decorrência de serem valores numéricos e ser possível visualizar todas as mudanças dos valores quantitativos ocorridas no município entre os anos de 2000 a 2019 (Tabela 02).

Observa-se que, da área total equivalente a 295.666 ha, a classe que ocupa maiores áreas é a de formação de floresta. Todavia, ao longo do tempo (de 2000 a 2019) houve diminuição de sua extensão de 66.231 ha. Essa redução acentuada nas áreas de floresta se deu em favor sobretudo da conversão desses espaços para áreas de pastos. 


\section{ANÁLISE DE USO E COBERTURA DO SOLO ASSOCIADA A FOCOS DE CALOR NO MUNICÍPIO DE BANNACH - PA}

Tabela 02: Dados Anual de Uso e Cobertura do Solo no município de Bannach-PA.

\begin{tabular}{|c|c|c|c|c|c|c|c|c|c|c|}
\hline \multirow[b]{2}{*}{ Classes } & \multicolumn{2}{|l|}{2000} & \multicolumn{2}{|l|}{2005} & \multicolumn{2}{|l|}{2010} & \multicolumn{2}{|l|}{2015} & \multicolumn{2}{|l|}{2019} \\
\hline & Ha & $\%$ & Ha & $\%$ & Ha & $\%$ & Ha & $\%$ & Ha & $\%$ \\
\hline Floresta & $\begin{array}{l}152.61 \\
5\end{array}$ & 51,62 & $\begin{array}{l}116.84 \\
9\end{array}$ & 39,52 & 91.911 & 31,09 & 89.501 & 30,27 & 86.384 & 29,22 \\
\hline $\begin{array}{l}\text { Formação } \\
\text { Natural não } \\
\text { Floresta }\end{array}$ & 3.416 & 1,16 & 4.208 & 1,42 & 4.541 & 1,53 & 4.521 & 1,53 & 4.548 & 1,54 \\
\hline Agropecuária & $\begin{array}{l}139.50 \\
3\end{array}$ & 47,18 & $\begin{array}{l}174.41 \\
2\end{array}$ & 58,99 & 199.005 & 67,31 & 201.410 & 68,12 & 204.572 & 69,19 \\
\hline $\begin{array}{ll}\text { Área } & \text { não } \\
\text { vegetada } & \end{array}$ & 30 & 0,00 & 33 & 0,00 & 39 & 0,00 & 44 & 0,00 & 48 & 0,01 \\
\hline Copo D’Água & 99 & 0,04 & 162 & 0,07 & 168 & 0,07 & 187 & 0,08 & 106 & 0,04 \\
\hline Total geral & 295666 & $100 \%$ & 295664 & $100 \%$ & 295664 & $100 \%$ & 295663 & $100 \%$ & 295658 & $100 \%$ \\
\hline
\end{tabular}

Elaborado com base nos dados do MapBiomas. Fonte: Autores (2021)

Desse modo, a classe floresta apresentou perda de 66.231 ha de área, ao qual no ano de 2000 evidencia-se 51,62 \% e em 2019 o valor percentual de área foi de 29,22\%, representando perda total de 56,20\% de floresta em relação a 2000.

Como resultado da classe de agropecuária está espacialmente concentrada praticamente por toda extensão territorial do município de Bannach existindo uma mínima participação na região Oeste do município em favor desse espaço abrigar uma área de domínio indigena mais especificamente a Terra Indígena Kayapó.

No presente estudo, ao contrário da classe de floresta evidencia-se que, a classe agropecuária saltou de 139.503 hectares para 204.572 hectares, equivalente a um aumento de 46,64\% de área. Nesse tocante, a agropecuária retrata grande parte da economia local, devido a mesma ser uma região com localização geográfica favorável para tal atividade. Assim, tendo em vista que agropecuária é a principal atividade econômica e que promove maiores ações e alterações no meio ambiente nos municípios amazônicos o cenário não diverge na cidade de Bannach, pois os maiores impactos ambientais ocasionados na região do sudeste paraense são oriundos do desmatamento ocasionado principalmente por atividades de agricultura, mineração e pecuária principalmente. Alho et al., (2019) assume que a vegetação arbustiva, sem a presença do rebanho bovino, atinge até dois metros de altura, já com a inserção do gado, além do pisoteio e compactação do solo, impede do acúmulo de biomassa, consequentemente alterando o habitat natural. 
Nesse contexto, com o momento atual e caótico que a Amazônia vivência com relação a degradação da floresta e uso descontrolado dos recursos naturais dos territórios amazônicos. É inquestionável que seja pensado e adotado modelos de produção mais sustentável que concilie produção e conservação do meio ambiente, buscando alternativas para ir de encontro com soluções mais assertivas no sentido de minimizar essa problemática do desmatamento e das queimadas e do processo degradativo na região.

Assim, estratégias sustentáveis de recuperação de áreas degradadas em decorrência das formas de uso da terra que visem o manejo adequado do solo e a recomposição do meio ambiente como da biodiversidade florística são de grande importância para o restabelecimento da funcionalidade do ecossistema e desenvolvimento agropecuário (PEZARICO et al., 2013).

No caso da Amazônia, que têm evidenciado intensivas mudanças climáticas globais e de crise econômica mundial, devido ao intenso processo de desmatamento e de queimadas nas últimas décadas parece evidente e urge a necessidade de implantação de sistemas de produção de alimentos mais sustentáveis, com relação ao uso da terra objetivando à mitigação de emissões de carbono para a atmosfera e de menos impactos ao meio ambiente (PORRO,2009), os SAF se apresentam como uma opção.

Face a essa abordagem, os SAF são agroecossistemas com o uso de práticas mais sustentáveis no manejo e no uso da terra combinando diferentes arranjos nesse sistema como arranjos de espécies agrícolas, florestais e/ou animais em uma mesma área de cultivo. Assim, temos que implantação de Sistemas Agroflorestais (SAF) em larga escala nos sistemas de produção dos agricultores familiares são excelentes alternativas de enfrentamento a essa realidade de desflorestamento e impactos reduzidos em territórios amazônicos, em decorrência dos SAF promover elementos essenciais para a manutenção e preservação da qualidade do solo, como a ação dos sistemas radiculares que podem vir a promover a ciclagem de nutrientes e funcionam como potencial protetor do solo, principalmente no que se refere à recuperação de áreas degradadas ao longo dos anos devido ao intensivo manejo inadequado (MASCARENHAS et al., 2017).

Agregue-se a todo esse contexto, o emprego dos SAF por ser uma forma de manejo que consegue aliar produção e conservação da biodiversidade dos ecossistemas locais e tradição, preservando recursos da paisagem, água e solo (ALTIERI et al., 2012). Dessa maneira, esses sistemas são alternativas viáveis de produção para agricultura familiar, pois favorecem o desenvolvimento dos territórios baseado em um modelo que aperfeiçoa os valores sociais, culturais e ambientais, auxiliando o pequeno produtor na escolha de práticas sustentáveis de produção (PEZARICO, 2013). 


\section{ANÁLISE DE USO E COBERTURA DO SOLO ASSOCIADA A FOCOS DE CALOR NO MUNICÍPIO DE BANNACH - PA}

Com relação às demais classes analisadas (Tabela 02), verificou-se que a classe área não vegetada apresentou menores valores, e a classe corpo d'água permaneceu estável durante toda a série analisada.

\section{CONCLUSÕES}

O município de Bannach registrou no intervalo estudado um total de 8.934 focos de queimadas. No quantitativo anual, em 2005 houve a maior número de focos, com 2.687 registros, seguido do ano seguinte em 2010, com 2.282 ocorrências, sendo que, do total percentual registrado durante os anos analisados, 2000 representou cerca de 3,29\% dos focos e em seguida, 2005 com 30,08\%, 2010 com 25,55\%, 2015 com 22,85\% e 2019 com 18,23\%.

A expansão das atividades agropecuárias na região amazônica, são as principais causas das mudanças da paisagem, do bioma e dos ecossistemas locais. Nesse sentido, urge a necessidade de que seja adotado e implantado modelos de produções mais sustentáveis como forma de mitigar tais problemáticas com relação ao desmatamento e das queimadas nos municípios amazônicos. Os SAF é uma opção, para esse processo, pois esse modelo de produção é possível os produtores aliar produção e conservação com impactos ambientais reduzidos. Haja visto, que com a implantação dos SAF nas propriedades agrícolas o desmatamento e as queimadas são substituídos por outras técnicas de manejo mais sustentáveis, com a inserção de várias espécies florestais, onde os resíduos da floresta tem o seu reaproveitamento pela ciclagem de nutrientes e tendo como principal característica a recomposição florística, que contribui para a recomposição do meio ambiente o que é de extrema importância para o desenvolvimento dos agroecossistemas agrícolas e para funcionalidade dos ecossistemas e manutenção da fauna e flora. Assim, os SAF são alternativas viáveis de enfrentamento dessa realidade de fogo e desmatamento na Amazônia.

Por fim, aliada a essas premissas, o conhecimento de geoprocessamento, especialmente sobre os Sistemas de Informações Geográficas (SIG), mostrou-se como uma técnica bastante promissora e de total importância para detecção e quantificação dos focos de calor e alcance de resultados de dados espacializados, através de ferramentas relevantes, pois essas informações são necessárias para o delineamento de políticas públicas para a prevenção, monitoramento e ao combate das queimadas nos municípios amazônicos.

\section{REFERÊNCIAS}

ALHO, C. J. R. et al. (2019). Ameaças à biodiversidade do Pantanal Brasileiro pelo uso e 
ocupação da terra. Ambiente e Sociedade, 22, e01891.

ALTIERI, M. A.; FUNES-MONZOTE, F. R.; PETERSEN, P. Agroecologically efficient agricultural systems for smallholder farmers: contributions to food sovereignty. Agronomy For Sustainable Development, v. 32, p.1-13, 14 out. 2012.

ARRAES, Christiano Luna et al. Estimativa da taxa de desmatamento do município de bannach, pará-amazônia legal, utilizando imagens landsat5/tm. Revista de Ciências Agrárias, v. 33, n. 2, p. 231-243, 2010.

BASTOS, T. X., Silva, G., Pacheco, N. A., \& Figueiredo, R. D. O. (2006). Informações agroclimáticas do município de Paragominas para o planejamento agrícola. In Embrapa Amazônia Oriental-Artigo em anais de congresso (ALICE). In: Congresso Brasileiro de Meteorologia, 14., 2006, Florianópolis. Anais... Florianópolis: SBMET. Disponível em:<https://www.alice.cnptia.embrapa.br/handle/doc/579613>. Acesso em: 01 mai 2021.

BERENGUER, Erika. Pesquisadora sobre fogo na Amazônia explica real situação da floresta. Ciclo Vivo. 2019. Disponível em: <https://ciclovivo.com.br/planeta/meioambiente/pesquisadora-fogo-amazonia-explica-real-situacao-floresta/>. Acesso em: 03 jun 2021.

BURROUGH, P. A. \& MCDONNELL, R. A. Principles of Geographical Information Systems. Oxford: Oxford University Press, 1998.

DRUCK, SUZANA. et al.. Análise espacial de dados geográficos. Planaltina, DF: EMBRAPA Cerrados, 2004.

FERNANDES T (2019). Dinâmica espaço - temporal de focos de queimadas na área fisiográfica da microrregião de Parauapebas - pa, BRASIL. Revista Gestão \& Sustentabilidade Ambiental 8(1);340-364. Disponível em: < http://portaldeperiodicos.unisul.br/index.php/gestao_ambiental/article/view/6381> . Acesso em: 03 mai 2021.

FILHO, M.; SOUZA, J. C. É possível superar a herança da ditadura brasileira (1964-1985) e controlar o desmatamento na Amazônia? Não, enquanto a pecuária bovina prosseguir como principal vetor de desmatamento. Boletim do Museu Paraense Emílio Goeldi. Ciências Humanas, v. 9, n. 1, p. 219-241, 2014.

HUESCA, M., LITAGO, J., MERINO-DE-MIGUEL, V. S., CICUENDEZ, L. O., PALACIOSORUETA, A. (2014). Modeling and forecasting MODIS-based Fire Potential Index on a pixel basis using time seriesmodels. International Journal of Applied Earth Observation and Geoinformation, 26, 363-376.

IBGE, Instituto Brasileiro de Geografia e Estatistica, Cidades. Disponivel em: < https://cidades.ibge.gov.br/brasil/pa/bannach>. Acesso em 01 de set 2021.

INPE. INSTITUTO NACIONAL DE PESQUISAS ESPACIAIS. Portal de Monitoramento de Queimadas e Incêndios. Disponível em < http://www.inpe.br/queimadas>. Acesso em 03 de jun 2021. 


\section{ANÁLISE DE USO E COBERTURA DO SOLO ASSOCIADA A FOCOS DE CALOR NO MUNICÍPIO DE BANNACH - PA}

IPAM, INSTITUTO DE PESQUISA AMBIENTAL DA AMAZÔNIA. Disponível em:< https://ipam.org.br/wp-content/uploads/2019/08/NT-Fogo-Amazo\%CC\%82nia-2019.pdf.>.

LORENA, R. B. (2003). Evolução do uso da terra em porção da Amazônia ocidental (Acre), com uso de técnicas de detecção de mudanças. Doctoral dissertation, Dissertação de mestrado. INPE. São José dos Campos. Disponível em:< http://marte.sid.inpe.br/col/ltid.inpe.br/sbsr/2002/11.13.12.20/doc/06_129.pdf >. Acesso em: 05 mai 2021.

MAPBIOMAS. Projeto MapBiomas - Coleção 3.1 da Série Anual de Mapas de Cobertura e Uso de Solo do Brasil. Disponível em: < http://mapbiomas.org/pages/database/mapbiomas_collection>. Acesso em 16 de mar de 2021.

MARTINEZ, L.L.; Fiedler N.C. Lucatelli G.J. (2007) - Análise das relações entre desflorestamentos e focos de calor. Estudo de caso nos municípios de Altamira e São Félix do Xingu, no Estado do Pará. Revista Árvore(on line) 31, 4: 695-702.

MASCARENHAS, A. R. P.; SCCOTI, M. S. V.; MELO, R. R.; CORREAA, F. L. O.; SOUZA, E. F. M.; ANDRADE, R. A.; MÜLLER, M. W. Atributos físicos e estoques de carbono do solo sob diferentes usos da terra em Rondônia, Amazônia Sul-Ocidental. Pesquisa Florestal Brasileira, Brasília, DF, v. 37, n. 89, p. 19-27, 2017.

MENESES, P. R.; ALMEIDA, T. D. Introdução ao Processamento de Imagens de Sensoriamento Remoto. Brasília: Universidade de Brasília, 2012.

PEZARICO, C. R. et al. Indicadores de qualidade do solo em sistemas agroflorestais. Revista de Ciências Agrarias - Amazon Journal Of Agricultural And Environmental Sciences, [s.1.], v. 56, n. 1, p.40-47, 2013.

PORRO, R. Expectativas e desafios para a adoção da alternativa agroflorestal na Amazônia em transformação. In: PORRO, R. Alternativa agroflorestal na Amazônia em transformação. 1. ed. Brasília: Embrapa, 2009. p. 33-51.

RAMOS, A. B. R.; NASCIMENTO, E. R. P.; OLIVEIRA, M. J.. Temporada de incêndios florestais no Brasil em 2010: análise de série histórica de 2005 a 2010 e as influências das chuvas e do desmatamento na quantidade dos focos de calor. In: SIMPÓSIO BRASILEIRO DE SENSORIAMENTO REMOTO (SBSR), 15. Anais. São José dos Campos: INPE, 2011.

RAMOS, L. F; OLIVEIRA, M. R.; SORIANO, B. M. A. Análise da distribuição de focos de calor no Pantanal brasileiro em 2017. In: Embrapa Pantanal-Resumo em anais de congresso (ALICE). In: EVENTO DE INICIAÇÃO CIENTÍFICA DO PANTANAL, 6.; SEMANA DA BIOLOGIA, 13., 2018, Corumbá. Resumos... Brasília, DF: Embrapa, 2018.30 p., 2018.

RIVERO, S.L.M.; ALMEIDA, O.T.; ÁVILA, S.; SOUZA, W.O.. Pecuária e desmatamento: uma analise das principais causas diretas do desmatamento na Amazônia. Nova economia Belo Horizonte, v. 19, n. 1, p. 41-66, 2009.

RODRIGUES, J. B. et al. Análise de focos de queimadas no município de Balsas/MA. Nature and Conservation, v. 13, n. 3, p. 146-151, 2020. 
SALES, G. M., PEREIRA, J. L. G., THALÊS, M. C., POCCARD-CHAPUIS, R., DE ALMEIDA, A. S. (2019). Emprego dos focos de calor na avaliação das queimadas e em incêndios florestais em Paragominas, Pará, Brasil. Boletim do Museu Paraense Emílio GoeldiCiências Naturais, 14(1), 55-77. Disponível em:< https://boletimcn.museugoeldi.br/bcnaturais/article/view/140> .Acesso em: 04 mai 2021.

SANTOS, G. G et al. USO DE GEOTECNOLOGIAS NA ANÁLISE ESPACIAL DOS FOCOS DE CALOR NO MUNICÍPIO DE SÃO FÉLIX DO XINGU, PARÁ. Geografia: Publicações Avulsas, v. 2, n. 1, p. 395-419, 2020.

SCHROEDER, W., ALENCAR, A., ARIMA, E., SETZER, A. The spatial distribution and interannual variability of fire in Amazonia. Amazonia and Global Change, p.43-60, 2009.

SORIANO, B. M. A., CARDOSO, E. L., TOMÁS, W. M., SANTOS, S. A., CRISPIM, S. M. A., \& PELLEGRIN, L.A. (2020). Uso do fogo para manejo da vegetação no Pantanal. Embrapa Pantanal, 164 (1), 1-17.

SOUZA, Manuela Braga de et al. Dinâmica de uso e cobertura do solo associada a focos de calor no Município de Poconé-MT. Research, Society and Development, v. 10, n. 3, p. e0710312930-e0710312930, 2021.

THOMAZ, E. L.; ANTONELI, V.; DOERR, S. H. Effects of fire on the physicochemical properties of soil in a slash-andburn agriculture. Catena, v. 122, p. 209-215, 2014. Disponível em: https://www.sciencedirect.com/science/article/pii/S0341816214001921.

THOMAZ, E. L.; ANTONELI, V.; DOERR, S. H. Effects of fire on the physicochemical properties of soil in a slashandburn agriculture. Catena, Amsterdam, v. 122, p. 209- 215, 2014.

VAN DER WERF, G. R., RANDERSON, J. T., GIGLIO, L., COLlATZ, G. J., Mu, M., KASIBHATLA, P. S., VAN LEEUWEN, T. T. Global fire emissions and the contribution of deforestation, savanna, forest, agricultural, and peat fires (1997-2009). Atmospheric Chemistry and Physics, v.10, n. 23, p. 11707-11735, 2010.

VASCONCELOS, S. S, FEARNSIDE, P. M., TEIXEIRA-SILVA, P. R., DIAS, D. V., \& GRAÇA, P. M. L. D. A. Suscetibilidade da vegetação ao fogo no sul do Amazonas sob condições meteorológicas atípicas durante a seca de 2005. Revista Brasileira de Meteorologia, v.30, n.2, 134 - 144, 2015.

ZAIDAN, R. T., Geoprocessamento Conceitos e Definições. Revista de Geografia PPGEOUFJF, v. 7, n. 2, 2017. 